\title{
O Conceito de Justo Preço nas Cooperativas de Produtores
}

\author{
Walmor Franke \\ Magistrado aposentado; ex-Membro do \\ Conselho Nacional de Cooperativismo
}

Segundo os teóricos do "Socialismo Cooperativo", o novo ordenamento social que preconizam e o qual, com a implantação do reinado do "justo preço", conciliaria o princípio da justiça na repartição das riquezas com o da eficácia na produção de bens materiais num regime de respeito à liberdade dos indivíduos, somente seria possivel mediante o cooperativismo de consumo. ${ }^{1}$

Pouco ou nada restaria às cooperativas de produtores (ou de produção) na edificação do novo regime. Embora não cheguem a negar o importante papel econômico e social que essas organizações exercem no contexto do atual sistema capitalista, reduzem, porém, ao mínimo o valor de sua influência na instauração da nova ordem, por não estarem elas obedecendo, na sua atuação, aos princípios da verdadeira cooperação, já que, ao invés de praticarem a política do "justo preço", tenderiam elas, via de regra, à obtenção do preço máximo.

São palavras de LAVERGNE: "As associações obreiras de produção, as cooperativas agrícolas de compra em grosso de adubos, sementes, máquinas aratórias ou de venda de produtos agrícolas, as cooperativas artesanais de compra de artigos necessários ao exercício de suas profissões exercem um papel econômico não só muito interessante, como, até mesmo, capital; assim, somente por intermédio das cooperativas agrícolas,

1 - LAVERGNE: "Vender con peso completo y a un precio justo articulos de buena caAtribut es la razón de ser de las cooperativas distributivas" (apud JOAQUíN F. VERA, Atributos y Proyecciones del Cooperativismo, B. Aires 1967, pág. 67). 
a pequena média agricultura francesa consegue modernizar os seus métodos. Mas, visando à obtenção do benefício máximo em favor dos seus membros e não à redução do custo de vida, tais sociedades não apresentam nenhuma relação com a edificação do socialismo cooperativo. ${ }^{2}$

2. O ceticismo de LAVERGNE em relação às cooperativas de produtores resulta de um conflito visível entre uma construção ideológica - o desejado Socialismo Cooperativo - e a realidade do meio capitalista em que, necessariamente, atuam as empresas cooperativas, com suas diversas modalidades, na defesa das economias associadas.

No que respeita à política de preços, mostra a experiência que no interesse da otimização dos serviços prestados aos cooperadores, as cooperativas procuram assegurar-se uma posição favorável no mercado, esforçando-se por alcançar baixos preços de compra (para as economias cooperadas: baixos custos) e altos preços de venda (para as economias associadas: altos resultados). ${ }^{3}$

Aliás, se assim não procedessem, difícil, por certo, thes seria cumprir sua missão fundamental, que é a de proteger, fomentar e desenvolver as economias particulares dos sócios (domésticas, agrícolas, artesanais, etc), com o menor risco possível ao mais baixo custo, competindo, em regime de mercado, com as demais empresas. Essa missão, a cooperativa só a realiza satisfatoriamente, quando capacitada para o exercício da concorrência, pois "também em relação às cooperativas vale o critério da rentabilidade". 4

Como acentua BOGARDUS: "La cooperativa es una unidade original dentro de una economia mixta. Funciona entre la economia comercial del sector privado, donde los riesgos son considerables, y la economia del sector público, donde las decisiones se tomam por toda la nación. ${ }^{5}$

Poder-se-ia dizer, com maior rigor, com o Prof. WILHEM WEBER, que o setor cooperativo, de que se ocupou FAUQUET, na realidade não existe como unidade independente, como setor autônomo ao lado dos outros, mas, apenas, como complemen-

2 - BERNARD LAVERGNE, Le Socialisme Coopératif, pág. 9

$3-$ Cf. REINHOLD HENZLER, Betriebswirtschaftliche Problem 9.

4 - GEORG

Internacional de Cooperativismo sobre teses económicas apresentadas no $4 .^{\circ}$ Congresso senschaftswesen, v. 14, ano 1964, pág. 330 . 1963, in "Zeitschrift für das gesamte Genos5 - Principios

ed. 1964. pág. 175. 
tação, dentro dos demais setores privados do sistema econômico, como seja no setor doméstico (através das cooperativas de consumo), no setor agrícola, etc. ${ }^{6}$

No sistema econômico capitalista, as cooperativas concorrem com as empresas de capital, não podendo, por isso, subtrair-se, sem graves riscos, às leis gerais que regulam os respectivos mercados.

Aliás, na opinião de ponderável corrente de doutrinadores, a cooperação não pode ser considerada como sistema "único" e "global" (FAUQUET, TSHAIANOV, LASZLO VALKO, HANSJÜRGEN SERAPHIM, etc.). Como assinala MARGUERITE CAMBOULIVES, a cooperação também foi concebida na Europa como sistema global. Mas a "República Cooperativa", idealizada por GIDE, jamais chegou a realizar-se. As estruturas cooperativas não puderam estabelecê-la na competição econômica com as empresas capitalistas, fortemente implantadas. Resta a certeza de terem as cooperativas constituído um freio moderador do capitalista liberal, servindo, ao demais, de meio indireto de intervenção do Estado na organização econômica. ${ }^{7}$

"O cooperativismo - pondera o Prof. HANS-JÜRGEN SERAPHIM - surgiu como reação ao capitalismo liberal. Isso, porém, não quer dizer que a sua base seja socialista e, muito menos, coletivista. Outra questão é saber se dos seus funda. mentos poderá desenvolver-se, em regime de liberdade, uma ordem socialista abrangente, como o pretende o assim denominado Socialismo Cooperativo. Imperioso não é o desenvolvimento em tal direção, e a evolução efetiva do cooperativismo também mostra que essa direção não foi seguida". 8

Dentro da mesma linha de pensamento, acentua LASZLO VALKO: "A associação cooperativa, vista com realismo, desempenha importantíssimo papel na economia do Estado moderno, mas as cooperativas não se organizam para constituir um monopólio ou para acarretar uma mudança revolucionária nas relações sociais ou, ainda, para conduzir à implantação de um Estado Cooperativo". 9

\footnotetext{
6 - Cf. "Das Verhältniss Staat - Genossenschaften in Oestreich" "in Zeitschrift für das gesamte Genossenschaftswesen, vol. 24, ano 1964, pág. 148.

7 - L'Organisation Coopérative du Sénégal, Paris 1967, "Introduction".

in Vom "Das ökonomische und soziale Wesen der Erwerbs - und Wirtschaftsgenossenschaften", 9 Vom Wesen der Genossenschaften und ihre steuerliche Behandlung, ed. 1951, pág. 58-59.

Wirts Cf. "A natureza económica da cooperativa nas suas relações com o Estado" (Das

Iür

das gesamte Genossenschaftswesen", vol. 14, ano 1964, pág. 180.
} 
3. Caracterizado como instrumento de defesa, não só de posições econômicas dignas de proteção, senão também de valores éticos e jurídicos intimamente vinculados ao direito individual de liberdade, proclamado como conquista dos modernos Estados de Direito, o cooperativismo vem sendo conceituado, nos tempos modernos, por amplas áreas do pensamento científico, na esteira de escritores ilustres como VALENTI, FAUQUET e outros, como fenômeno setorial do sistema econômico dominante, destinado a corrigir-lhe os abusos e as distorções.

VALENTI, entre os estudiosos clássicos do associativismo cooperativo, já concluíra, como assinala GUELFAT, que "a Cooperação não constitui um sistema econômico em si; ela não é mais do que um setor do sistema econômico existente. A função da Cooperação não é senão auxiliar e, portanto, limitada; compete-lhe servir de "corretivo" ao sistema de repartição em um regime de livre concorrência, adaptando-se às suas leis". ${ }^{10}$

E não é outra a conclusão a que chega HELMUT FAUST na sua excelente "História do Movimento Cooperativo", publicada em 1966, onde, após mostrar as razões econômicas e sociais, determinantes das diversas formas cooperativas surgidas no século passado, afirma:

"As cooperativas representam, como um todo, uma potência econômica, mas, sem embargo disso, constituem apenas um "setor" da economia global. Excetuados alguns ramos, nada autoriza falar em preponderância das organizações cooperativas em face de outros grupos econômicos, muito menos em uma "cooperativização" da economia. O universalismo cooperativista não está incluído nos objetivos das sociedades cooperativas. Edificadas sobre o princípio da adesão voluntária, repugna-lhes a conquista de situações monopolísticas; antes, o que elas querem é romper os monopólios. Elas se servem de métodos defensivos e não, ofensivos; ao demais, não contrariam a concepção de que a economia social só tende a lucrar com a diversificação, em número e qualidade, dos tipos empresariais nela representados". 11

4. Feita abstração da sedutora idéia de que por intermédio da associação cooperativa, não compulsória, mas democrática, independente e livre, se possa alcançar a cooperativização inte-

10 - ISAAC GUELFAT, La Coopération devant la Science Économique, Paris, 1966, pág. 25.
11 - "Geschichte der Genossenschaftsbewegung", 1965, pág. 463.

R. Serv. públ., Brasilia, 108 (3) set./dez. 1973 
gral da vida econômica ${ }^{12}$ e considerada a cooperativa como empreendimento comum, para não dizer comunitário, ${ }^{13}$ destinado especificamente a servir aos sócios, como órgão de ligação com o mercado, na defesa e no fomento de suas economias particulares, não há negar que, tanto na área do consumo, quanto na da produção, as cooperativas, quando tecnicamente habilitadas para o exercício da concorrência, realizarão, sob qualquer de suas modalidades, relevante missão social.

O princípio da rentabilidade que, na defesa das economias associadas, necessariamente deve ser observado pelas cooperativas, não conflita, mas antes sintoniza, com a tarefa que lhes incumbe desempenhar no ambiente de mercado. É certo que essa "rentabilidade" não deve ser procurada à custa dos associados ou como "um fim em si", mas, conforme adverte o Prof. HANS-JÜRGEN SERAPHIM, "somente no conceito e até o limite de assegurar a capacidade de vida da cooperativa, para que se mantenha em condições de prestar serviços". ${ }^{14}$

Não conflita igualmente com a essência do cooperativismo que as cooperativas de produtores, quase sempre constituídas de pessoas economicamente débeis, observem, na sua política de preços, os vigorantes no mercado. $O$ que seria desarrazoado é que essas cooperativas praticassem, como sistema, uma politica de preços reduzidos, pois é precisamente para furtar-se à coação de vender a baixo preço que o pequeno produtor se vale da união cooperativa.

"Os pequenos produtores agrupados em cooperativas, ensina TOUGAN BARANOWSKY, constituem a camada mais fraca

\footnotetext{
12 - A convivŝncia do setor cooperativo com o setor capitalista também, entre nós, foi admitida por GREDILHA no seguinte passo: "Há ainda uma observação a notar: é que o princípio da supressão do intermediário năo deve ser levado ao exagero, até supor-se que capitalíativismo pretenda a extinçăo do comércio e da indústria, na forma de atividade capitalistica; mas sim, que possibilite emparelhar, em igualdade de condiçőes e força ecorômica, formando - de lado o cooperativismo (uniăo de fracos, fortalecidos pela solidariedade de um por todos e todos por um) e do outro as organizaçőes capitalistas..." (Cf. ADOLPHO GREDILHA, Teoria e Prática do Cooperativismo, págs. 21-22).

13 - Na conhecida distinçăo que faz, do ponto de vista socióógico, entre Gemeinschaft (comunidade) e Gesellschaft (sociedade), FERDINAND TÖNNIES năo hesita em atribuir natureza comunitária às cooperativas, que, segundo observa, "han adquirido una gran imsortancia en la cuestion social dentro de la qual constituyen uno de los fenómenos más significativos, hasta por su mismo caráter, que no es solamente legal sino declaradamente pacifico, y no niega las relaciones básicas de la sociedad actual". E, rematando suas consideraçōes, adverte: "Este espiritu cooperativo es quizá la contracorriente de contenido comunitario que más perspectivas ofrece frente a la evolución societaria que ha marcado con sello poderoso, aunque no omnipotente, el conjunto de la economia moderna" (Principios 14 Sociologia, trad. esp. de VICENTE LLORENS, págs. 73 e 75).

14 - Op. cit. pág. 61 - Esse pensamento também está implicito na liçăo de GIDE, quando indispen no conceito de justo preço o requisito de que o preço contenha "les élements au consables pour que la production de la marchandise puisse continuer" (Leçons faites tique, College de France sur le juste prix, apud REBOUD et GUITTON, Précís d'Économie Politique, 9.a ed., t. I, pág. 513).
} 
da economia capitalista e a ação cooperativa desses pequenos produtores tem por fim principal subtraí-los à necessidade de venderem seus produtos a preços reduzidos". ${ }^{15}$

Exigir, como imperativo intrínseco da cooperação, de inspiração rochdaleana, que as cooperativas de produtores adotem preços rebaixados ou inferiores aos preços correntes, seria criar-lhes dificuldades intransponíveis ao exercício da função, que lhes compete, de servir, com eficiência, as economias cooperadas.

5. Releva notar que a noção de "justo preço" é altamente polêmica. Como adverte GUITTON, "sob a palavra justo dissimulam-se duas idéias. A de Justiça e a de justeza. Quando se diz justo preço, pensa-se num ideal de justiça; quando se fala em preço justo, alude-se à justeza". ${ }^{16}$

A noção de "justo preço", elaborada pela doutrina para as cooperativas de consumo é um conceito relativo, pois equivale, grosso modo, a "preço-de-compra" mais "despesas empresariais cooperativas", ou, em outras palavras, "preço fixado ao sócio" menos "sobra retornada". Segundo GIDE, é mediante a devolução do "trop perçus", ou seja da parcela que a cooperativa de consumo cobrou além do preço-de-custo e das despesas - parcela que seria o lucro do intermediário - que ela realiza, na prática, o princípio solidarista do "justo preço". ${ }^{17}$

$\mathrm{Na}$ verdade, o preço assim fixado corresponde antes, nas relações internas da cooperativa, à noção de preço justo, à qual se refere GUITTON, do que à de justo preço, considerado como realização de um critério absoluto de justiça na estimação do valor de troca da coisa. Basta sinalar que se o preçode-compra pago pela cooperativa de consumo se situou, por qualquer razão, na faixa maiș alta dos preços de mercado, se ela, eventualmente, comprou mal a preço injusto, essa injustiça objetiva do preço-de-compra pago pela cooperativa repercutirá diretamente sobre a posição do associado que vier a adquirir a coisa por um custo ainda majorado com os acréscimos decorrentes das despesas operacionais.

15 - Apud ISAAC GUELFAT, op. cit., pág. 28.

pág. 259 .

DIM, Lisboa, 1908, GIDE, As Socledades Cooperativas de Consumo, trad. de RICARDO JARdadés Cooperativas, 5.a ed. págs. 97,115 e 123 . 
O conceito de "justo preço" dominante nas relações internas das cooperativas de consumo, não pode ser sumariamente transferido para as cooperativas de produção (ou de produtores), incumbidas de colocar a produção (em estado natural, beneficiada ou elaborada) nos mercados de venda ou de consumo.

Neste caso não se trata de preço a ser pago pelo cooperado, mas de preço a ser cobrado de terceiros, em regime de mercado, através da cooperativa, que atua como empreendimento comum auxiliar.

Qual, então, o critério para calcular o "justo preço" dos produtos transacionados por intermédio da cooperativa? Qual a política de preços a ser observada pela cooperativa na colocação dos bens produzidos, individual ou coletivamente, pelos sócios?

6. Como acentua KARL DIEHL, a idéia de "justum pretium" passou, no correr dos tempos, em consonância com o desenvolvimento da vida jurídica e econômica, por várias alterações.

Ao direito romano clássico era estranha a exigência de um preço proporcionado ao valor real da coisa, pois o pensamento que então predominava era a irrestrita liberdade das partes na conclusão do contrato de compra e venda. ${ }^{18}$ Entendiam os jurisconsultos daquela época que se devia dar liberdade às partes no sentido de auferir do contrato o máximo proveito pessoal. ${ }^{19}$

Proporcionado era o preço estabelecido, de comum acordo, pelas partes contratantes. O preço devia ser "certum", isto é, determinado ou suscetível de determinação de acordo com os elementos objetivos indicados no contrato. ${ }^{20}$ Além disso, devia ser "vero", "serio", isto é, não devia ser irrisório ou insignificante em relação ao valor da coisa. ${ }^{21}$

"Mais tarde, a expressão "justum pretium" também não chegou a envolver a idéia de um preço proporcionado, isto é, de um preço que correspondesse à eqüidade, à justiça ou a um sentimento popular; era, apenas, outra expressão para o

18 - SALVATORE DI MARZO, Istituzioni di Diritto Romano, 5.a ed., pág. 374.

19 - VICENZO ARANGIO-RUIZ, Istituzioni di Diritto Romano, 10.a ed., pág. 339.

20 - SALVATORE DI MARZO, op. cit., pág. 374.

21 - VAN WETTER, Pandectes, t. IV. Paris 1910, $\S 379$, pág. 17; E. PETIT, Tratado Ele. mental de Derecho Romano, trad. esp. de J. F. Gonzáles, n. 360 , pág. 391. 
"verum pretium". Quando, por exemplo, uma mercadoria não possuía a qualidade combinada, ou quando ocorria engano de um dos contraentes, o juiz devia estabelecer um "justum pretium". Opunha-se este ao preço de afeição.

"Sobre a maneira de mensurá-lo, manifesta-se PAULUS, aludindo a SEXTUS PEDIUS: 'Sextus quoque Pedius ait, pretia rerum non ex affectione, nec utilitate singulorum, sed communiter fungi'. Repelia-se, pois, o preço de afeição e exigiase que o juiz adotasse um valor normal, igual para todos, nas suas decisões. Não se afirmava, no entanto, que esse valor devia prevalecer na vida econômica em geral.

“As expressões 'verum' ou 'justum pretium' serviam para traduzir a idéia de um preço proporcionado ao valor normal de

Posteriormente, o direito justiniano, concluindo, como acentua DI MARZO, um desenvolvimento que tivera início no período pós-clássico, permitiu que o vendedor de um imóvel, que a houvesse vendido por preço inferior à metade do seu valor efetivo (laesio enormis), rescindisse o contrato. ${ }^{23} \mathrm{O}$ comprador podia evitar a rescisão, pagando o necessário para completar o preço correspondente ao valor real do imóvel (quod deèst justo pretio). Nada prova, porém, segundo PETIT, que a mesma solução fosse aplicada à venda de bens móveis. ${ }^{24}$

DIOCLECIANO, no edictum de pretiis rerum, venalium do ano 301, estabeleceu, para todo o Império Romano, um tabelamento de mercadorias e serviços de qualquer espécie, com previsão de pena de morte para os que exigissem ou pagassem ou pagassem um preço superior ao máximo legal. O "justo preço" era, assim, coativamente imposto, nada importando a vontade das partes. Na fixação dos preços do Edito, que, em parte, eram estabelecidos pelos diretores das fábricas ou pelos administradores dos armazéns imperiais, e, em parte, pelos collegia dos artesãos e pequenos comerciantes, deviam ser observados os custos normais de produção além de um lucro suficiente, com exclusão de todo lucro comercial espe-
culativo. ${ }^{25}$ 22 - KARL DIEHL, "Theoretische Nationalökonomie, III, Lehre Von Der Zirkulation",

23 - SALVATORE DI MARZO, op. cit., pág. 374.

24 - E. PETIT, op. cit., pág. 391, nota 8.

25 - RUDOLF KAULLA, "Der Wertbegriff im römischen Recht", apud KARL DIEHL, op. cit.,
pág. 138. 
7. 'A doutrina do 'justo preço' - ensina KARL DIEHL obteve o seu verdadeiro desenvolvimento e fundamentação na Idade Média pela teoria canonística da usura. O conceito de 'usura' ia muito além da cobrança de juros. Usura, na doutrina dos canonistas, era tudo o que, na vida econômica, pudesse ser considerado como 'ganho excessivo'. A Igreja, que naquela época procurava controlar e supervisionar toda a vida econômica, combatia, sobretudo, o lucro comercial 'ilegítimo', o qual se verificava quando a mercadoria não era vendida ao 'justo preço'. O justum pretium não era idêntico ao preço de mercado, mas fixado em consonância com um critério de eqüidade e justiça. Esta concepção se fundava na teoria objetiva do valor, desenvolvida por ALBERTUS MAGNUS e TOMÁS DE AQUINO, apoiados, por sua vez, em idéias de ARISTÓTELES. De conformidade com a concepção tomística, a questão do justum pretium radicava nas exigências naturais do jus gentium. De acordo com essa doutrina, devia prevalecer, na troca, igualdade de prestação e contraprestação. Manifesta-se, aí, a essência da justitia commutativa. O valor dos produtos devia ser fixado em função do valor dos gastos realizados na sua produção. Sob esse aspecto, exigia-se igualdade de prestação e contraprestação.

"Mediante a fixação oficial dos preços - continua KARL DIEHL - a Igreja procurou tornar realidade o princípio do justum pretium. Mas, abstraindo a ação da Igreja, a formação dos preços, na Idade Média e no período posterior até o século XVIII, foi influenciada por toda sorte de tabelamentos, preços máximos e fixação estatal de preços. Além disso, em virtude do direito das corporações e da política mercantilista dominante, a formação dos preços, em grande escala, não era livre, mas legalmente vinculada". ${ }^{26}$

8. A ordem jurídica baseada na doutrina econômica liberal rompeu as amarras que impediam os movimentos do mercado livre. Vislumbrou-se na livre concorrência a solução para a implantação dos justos preços, que o intervencionismo estatal não fora capaz de realizar. Acreditou-se que, com o tempo, por efeito da livre competição, se formaria um preço médio de mercado, constituído pelo custo de produção acrescido de um lucro médio, estimulante da atividade empresarial, e que esse preço médio seria o preço "justo", já que a antiga intervenção estatal na regulação dos preços era, muitas vezes, acompanhada de privilégios e favorecimentos de toda espécie.

26 - KARL DIEHL, op. clt., págs. 138-139. 
A experiência mostrou o erro dessa teoria. Nas crises que se repetiam, havia preços que se situavam muito abaixo dos custos de produção, e nos períodos de conjuntura ascendente ocorriam preços excepcionalmente elevados. Para eliminar as violentas oscilações de preços, surgiram novas formas associativas, como ringues, sindicatos, cartéis, destinados a fixar, mediante convênios, preços mínimos e preços de orientação. A conseqüência foi o surgimento de preços monopolísticos, no âmbito, naturalmente, da esfera de influência dos cartéis, situação que, por sua vez, suscitou medidas legislativas que objetivavam corrigir os abusos dos monopólios. Ressurgia, dessarte, a idéia do justum pretium. Pretendia-se com a nova legislação compelir os cartéis, nas suas convenções, a não ultrapassar os preços "justos". 27

9. O problema do justo preço constitui, ainda hoje, objeto de interrogação na ciência econômica. A teoria, segundo a qual os preços dos bens se formam de acordo com os custos de produção, não encontra comprovação incontroversa nos fatos. Na economia capitalista ocorrem custos de conjuntura, custos diferenciais, custos de difícil previsão que, muitas vezes, anulam a escolha de qualquer critério razoável para o estabelecimento de justos preços de mercado.

Há fases, advertem REBOUD e GUITTON, em que o preço de uma mercadoria pode ser superior ou inferior ao seu custo de produção. "Pode ser-lhe superior, por exemplo, durante o período de febre e de especulação que precede uma crise, quando os compradores aceitam preços elevados na esperança de revender a mercadoria a um custo ainda mais alto ou quando a adquirem, não importa a que preço, para se desfazerem de um papel-moeda que se desvaloriza, dia a dia, cada vez mais. O preço é inferior ao custo, quando certos produtores vendem, sistematicamente, com prejuizos, determinados artigos, seja a título de propaganda, seja para arruinar os concorrentes, obrigando-os a acompanharem os preços rebaixados, sob pena de perder a clientela". ${ }^{28}$

Demais, como ensina ADOLF WEBER, "não só os preços das mercadorias dependem dos custos de produção como também, inversamente, os custos de produção dependem dos preços das mercadorias". 29

27 - Veja-se KARL DIEHL, op. et loc. cit. 28 - PAUL REBOUD et HENRI GUITTON, Précís d'Économie Politique, 9. a ed., tomo 1 ,

29 - ADOLF WEBER, “Kurzgefasste Volkswirtschaftslehre, pág. 96. 
Para mostrar a dificuldade que há em fixar "justos preços" para as mercadorias, cita ADOLF WEBER a pesquisa efetuada, na Alemanha, pela Comissão do Reich para Economia, sobre a formação dos custos de produção. Concluiu-se que "a extraordinária diferença na formação dos custos nas diversas empresas é na verdade subjugante", e que, em razão disso, "a determinação do justo preço, vale dizer, do preço justificado por todas as particularidades existentes em um mesmo ramo industrial... é uma impossibildade". Para citar um só exemplo (e não o mais grosseiro): Em uma indústria de bens de consumo a elaboração do produto, por unidade de peso, custou na fábrica de custo mais alto 227,50 marcos, na de custo mais baixo 19, e na de custo médio 54,30 marcos! A Comissão termina com a observação de que a procura do justo preço corresponde ao que foi na Idade Média a busca da pedra filosofal "que deveria resolver todos os enigmas do mundo; assemelhase às vãs tentativas de gerar artificialmente a vida humana nas retortas". 30

10. É certo que a fixação do "justo preço" das mercadorias continua a desafiar a argúcia dos estudiosos. Procura-se estabelecer o "fair price", com maior ou menor aproximação. Como acentua LUIZ SOUZA GOMES: - "Compreende-se que se todos os artigos de consumo pudessem ser fixados na base do "fair price", estariam satisfeitos produtores e consumidores. Mas o sistema é complexo e poucas mercadorias podem ser fixadas assim". 31

O problema se complica quando se trata da fixação de preços justos para os produtos da agricultura.

"A natureza comanda também a técnica agrícola: os imperativos químicos, físicos, meteorológicos, bacteriológicos, etc., determinam as condições de exploração. Os resultados escapam, em grande parte, às decisões prévias dos produtores. A oferta é aleatória. O homem fixa as superfícies semeadas, mas não os rendimentos. Aliás, a exploração agrícola pratica a policultura: é difícil imputar a tal produto a parte dos adiantamentos que the incumbem. Finalmente, a exploração encontra-se associada à vida da família. A racionalidade do cálculo dos custos agrícolas é difícil". ${ }^{32}$

30 - Op. et loc. cit.

31 - Cf. Dicionário Econômico-Comercial e Financeíro, pág. 144

pág. HENRI GUITTON, Economia Politica, trad. do Prof. OSCAR DIAS CORREA, vol. II, 
O que são os custos diferenciais na agricultura, mostranos KARL DIEHL, invocando a pesquisa efetuada a propósito por HOWARD:

"A denominada 'Lei fundamental da formação dos preços', de conformidade com a qual o nível dos preços seria determinado pelos custos de produção, encontra novas dificuldades por apresentarem tais custos, freqüentemente, sensiveis diferenças de empresa para empresa. É o que ocorre, particularmente, na produção agrícola. A dificuldade em calcular os custos de produção na agricultura foi exposta por HOWARD na sua obra: 'Os custos de produção dos nossos mais importantes produtos agrários' (3. ${ }^{\circ}$ ed., Berlim, 1908). 'O agricultor, assim diz HOWARD, encontra-se, sob esse aspecto, em muito má situação, inclusive o titular das explorações mais simples, não só porque produz muitas coisas a um só tempo, senão também porque não está ao seu alcance determinar a quantidade a ser produzida (ele só pode dimensionar os investimentos - qualidade e quantidade dos produtos são determinadas pelo solo e pelo tempo), e, ainda, porque ele não é, apenas, produtor, mas, igualmente, consumidor dos seus produtos, e muitas vezes fabricante, vendo-se compelido a industrializar sua produção para torná-la vendável. Quase cada um dos seus produtos exige ciclos diferentes, de seis meses a um ano (produtos agrícolas) ou até mesmo de alguns anos (produção de sementes, criação), em uma palavra: a economia mais sim. ples constitui-se numa multiplicidade de empreendimentos di. versos - nas mãos de um mesmo titular'. - Se as dificuldades são elas quando se trata de calcular o custo de um produto determinado. HOWARD esforçou-se, com o maior zelo, em proceder a esses cálculos, tomando por objeto mais de 2.500 economias diferentes, observando, porém, ele próprio, quanto ao valor dos seus cálculos: 'Todas as cifras obtidas pela forma exposta, somente valem para as economias respectivas, de cujos fundamentos contábeis foram extraídas. Talvez não se ajustem às relações econômicas do próximo vizinho. Não permitem conclusão a respeito da região ou ainda, da província, e quando se soma uma grande quantidade dessas cifras, para obter um valor médio, fica este dependendo da quantidade e do caráter casual dos resultados unitários utilizados'.

"Significativos - diz KARL DIEHL - são os cálculos de variáveis os custos de certos produtos. Os cálculos de 
HOWARD estendem-se a 140 unidades agrícolas. Ele calculou, por exemplo, os custos de produção de uma tonelada de trigo nessas 140 unidades, tomando por base um tempo médio de cinco anos e, em casos excepcionais, um período médio de três anos... HOWARD encontrou custos de produção de 3,87 até 11,69 marcos por tonelada de trigo: 'Quase nenhuma das cifras se repete, nem sequer é possível construir grupos de unidades econômicas semelhantes, até mesmo quando se colocam lado a lado todos os produtos e respectivos volumes. A cifra mais baixa e a mais alta diferem em cerca de $300 \%{ }^{\prime}{ }^{33}$

11. A existência de custos diferenciais acarreta dificuldades insuperáveis à fixação de "justos preços". O que seria "justo preço" para determinado produtor não o é para outro que opera, não importa por que motivo, com custo mais elevado. A lei do mercado é que produtos da mesma qualidade tendem a ter preços iguais, muito embora desiguais os seus custos de produção.

Todas essas particularidades inerentes ao processo produtivo são suficientes para afastar do âmbito da atividade das cooperativas de produção ou de produtores), a preocupação de realizarem, rigorosamente, nas suas transações, o regime do "justum pretium" - grandeza ideal que, como se viu, escapa, em regra, às possibilidades de mensuração, dadas as sensiveis, quando não extraordinárias, diferenças que ocorrem nos custos dos produtos. ${ }^{34}$

Atuando num meio capitalista, em regime concorrencial, as cooperativas de produtores (ou de produção) não se podem furtar às leis que regem as relações de mercado, tornando-selhes imperioso vender a preços conjunturais ou competitivos, embora com a probidade exigida pelos princípios do solidarismo cooperativista.

O cooperativismo de produção não é menos útil como elemento auxiliar das economias produtivas do que o cooperativismo de consumo, na complementação das economias domésticas.

33 - Cf. KARL DIEHL, op. cit. págs. 133-134.

34 - Nem nos orienta, no caso, a noçăo, por demais vaga, dada por GIDE no "Compêndio D'Economia Politica", trad. de F. CONTREIRAS RODRIGUES: - "Justo preço, isto é, preço tal que baste para cobrir todos os gastos de produçăo e satisfaça a todas as necessidades economicas que se resumem na formula da lei da oferta-e-procura, mas expurgado de todas as majoraçőes usurárias que só se devem à coligação dos produtores e à ignoráncia doa as difordores" (Cl. págs. 519-520). A fórmula năo diz como proceder quando săo grandes as diferenças nos custos de produçắo. 
Aliás, a simples presença das cooperativas de produtores nos mercados de consumo funciona como fator corretivo de manobras baixistas ensaiadas em detrimento de produtores primários, e como freio às tendências altistas de caráter meramente especulativo, a que, pela própria ideologia cooperativista dos seus diretores, se mostra infensa à grande maioria das organizações cooperativas.

"Se a fórmula cooperativa não se revela capaz de substituir sozinha o regime capitalista, ou de evitar sozinha o regime socialista, se tem a difícil vocação para a autonomia, parece, ao contrário, que poderá desempenhar sua missão verdadeira a título de complemento e correção do sistema capitalista. Permitindo o agrupamento dos indivíduos e das pequenas explorações, protegendo-os contra o domínio das grandes unidades capitalistas, surge como instituição auxiliar, capaz de equilibrar e moralizar o capitalismo". ${ }^{35}$

Empresa econômica, que opera em regime de competição, a política de preços da cooperativa, qualquer que seja a sua modalidade, deve obedecer ao princípio da "rentabilidade", no conceito de permitir-lhe uma satisfatória prestação de serviços. Preços não especulativos, mas compensadores, dentro dos limites da conjuntura e do mercado.

BORGADUS, abordando o tema com vistas ao comportamento empresarial cooperativo, teceu, a propósito, as seguintes considerações:

"La politica de los precios justos toma en consideración los custos de producción o transformación y el precio que razonablemente pueden pagar los consumidores. Reconoce la importancia que tienen los sueldos justos, tanto para los empleados del productor, como para los del distribuidor. Incluye un interés razonable sobre el capital de préstamo y un sobrecargo suficiente para dejar un margen seguro en caso de perdidas y de cambios repentinos en las condiciones del mercado e, de haber sobrecargos, su reembolso por prorrateo al consumidor se hace segund el volume de sus compras". ${ }^{36}$

35 - HENRI GUITTON, op. cit., vol. II, pág. 119

36 - Op. cit., págs. 175-176. 
E acaba concluindo: "Un precio justo de mercado es generalmente el precio normal del mercado. Dicha politica no favorece al vender a precios rebajados". ${ }^{37}$

Seria, efetivamente, temerário que as cooperativas de produtores, sob suas diversas formas, praticassem sistematicamente a política dos preços baixos, pois, ocorrendo prejuízos, não lhes seria fácil encontrar fora do círculo dos seus cooperados, também via de regra dotados de limitados recursos, quem as socorresse nas suas dificuldades.

As cooperativas devem operar, sem excessos nem exageros, mas racionalmente, com métodos empresariais, no interesse da própria sustentação do empreendimento comum cooperativo.

"Quando empreendimentos econômicos são postos a serviço de finalidades éticas, o seu êxito depende em primeira linha das possibilidades do êxito econômico e não do querer ético... uma orientação econômica viciada de erro conduz ao fracasso, ainda que esteja a serviço dos mais elevados escopos de natureza ética". ${ }^{38}$

12. Afirma-se que a divergência na política de preços constitui obstáculo à integração cooperativa.

Não se pode negar que a integração das cooperativas de consumo e as de produção em um sistema de interesses harmônicos e conjugados ainda não passa, de modo geral, dos limites de uma justificada aspiração do movimento cooperativista.

Ainda hoje, por certo, é digno de meditação e pronunciamento de J. MARCHAL:

"Válido para um setor, o princípio cooperativo não o é, quiçá, para todos. Não saberia ele satisfazer um sistema. Até mesmo entre os cooperativistas, há os que pensam e procu-

\footnotetext{
37 - Ibidem, pág. 176

Tanto para GIDE, como para LAVERGNE, só é verdadeiro, autêntico, o cooperativismo de consumo. Mas enquanto GIDE afirma: "Los cooperativistas creen que la libre competencia es impotente para obtener este resultado (o justo preço) y que es a ellos a quienes corresponde realizarlo", já LAVERGNE, dissentindo, declara: "Antes que nada, los cooperativistas deberán tratar de mantener siempre y en todas partes el máximo de competencia. Ésta es la idea sencilla y fuerte que debe sustituir a la idea imprecisa y inconsistente del justo precio" (apud JOAQUIN A. VERA, op. cit., págs, 67 e 77).

GRUENFELD-HILDEBRAND, "Genossenschftswesen", pág. 15.
} 
ram encontrar a solução em um convênio que reuniria as cooperativas de consumo, as únicas cooperativas verdadeiras, às cooperativas de produção e às cooperativas da agricultura. Mas o acordo é difícil: não existe regra quanto à fixação dos preços a serem estabelecidos nas relações dos diversos orga-
nismos". 39

MARCHAL admite que o cooperativismo "não saberia satisfazer um sistema". Mas, por outro lado, diz que as cooperativas de consumo "são as únicas cooperativas verdadeiras".

Recusar às cooperativas de produção ou às cooperativas agrícolas o caráter de cooperativas "verdadeiras", somente reconhecendo essa qualidade às cooperativas de consumo, implica, por si só, conceituar o cooperativismo como um sistema "único" ou "global", e não, apenas, como um setor do sistema capitalista, dotado da virtualidade de corrigir-lhe as distorções e os abusos. A unidade da economia cooperativista, dentro de um sistema econômico e jurídico global, edificado sobre os direitos de propriedade e liberdade e, sobretudo, sobre a livre iniciativa no processo produtivo, entretanto, como vimos, já não tem por si o pensamento de forte corrente de doutrinadores. $O$ que a realidade atual evidencia é que a cooperativa exerce uma função auxiliar na sustentação e no desenvolvimento das atividades econômicas dos seus membros, além de um poder corretivo e moderador das tendências especulativas da economia capitalista. A extraordinária importância desse papel no contexto da economia dominante é geralmente reconhecida até mesmo por aqueles que ainda se apegam à doutrina do "justum pretium" para atribuir unicamente às cooperativas de consumo a virtude de realizar esse objetivo tão difícil, quanto acariciado. A relatividade do conceito de "justo preço" até mesmo nas cooperativas de consumo, no âmbito da atual economia de mercado, já foi posta em relevo em anteriores considerações. ${ }^{40}$

Se a "entente", a que se refere MARCHAL, parece difícil nas condições atuais, não é ela, entretanto, impossível, tudo
dependendo da pujança, da maleabilidade e do sentido de res-
ponsabilidade dos a ponsabilidade dos agentes do movimento cooperativo. BOGARDUS nos cita um exemplo de relações intercoope-
perativas em que a política de preços considera ambas as posi-
ções: a dos produtores e a dos consumidores. ções: a dos produtores e a dos consumidores.

39 - Les Mecanismes des prix et la structure de l'Économie, Paris, 1942.
40 - Cf. pág. 18.

R. Serv. públ., Brasília, 108 (3) set./dez. 1973 
"En Noruega, por ejemplo, las mismas personas suelen desempeñar cargos en el consejo de administración de una cooperativa de producción y en el de otra de consumo. En dicha posición, uno naturalmente tiene presentes las necesidades del precio de venta de los productores y del precio de compra de los consumidores; no se favorece a uno más que al otro y se recomienda como precio una cifra intermedia". ${ }^{41}$

Como quer que seja, mesmo vendendo a preços de competição, as cooperativas de produtores (agricultores, criadores, etc.) auxiliam a seus membros e à economia em geral, corrigindo as tendências altistas da especulação mercantil, impedindo o aviltamento dos preços dos produtos primários e concorrendo, assim, para uma melhor e mais equitativa distribuição da riqueza coletiva. 


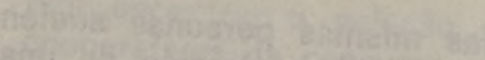

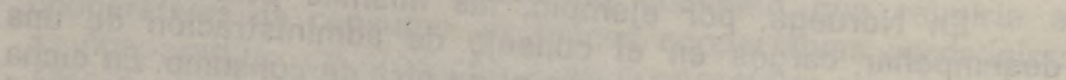

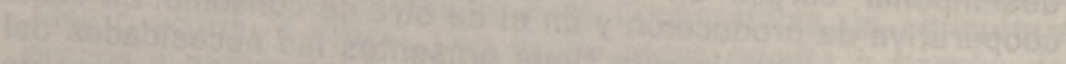

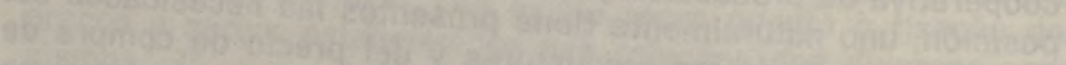

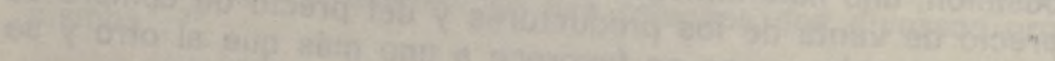

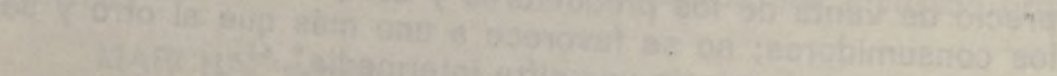

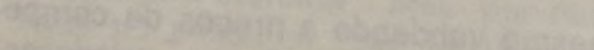

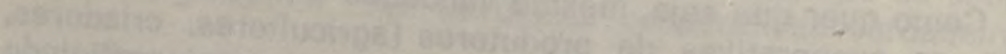

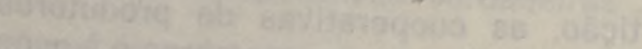
Q

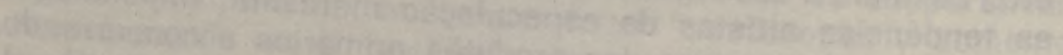

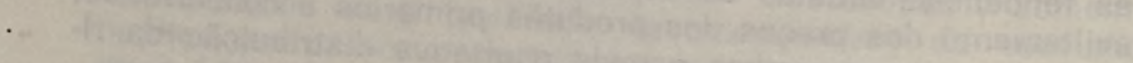

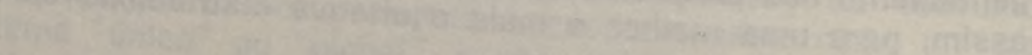
4.

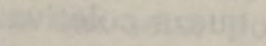
(3)

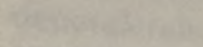

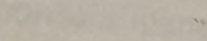

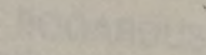

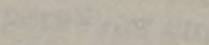

aㅏ. 